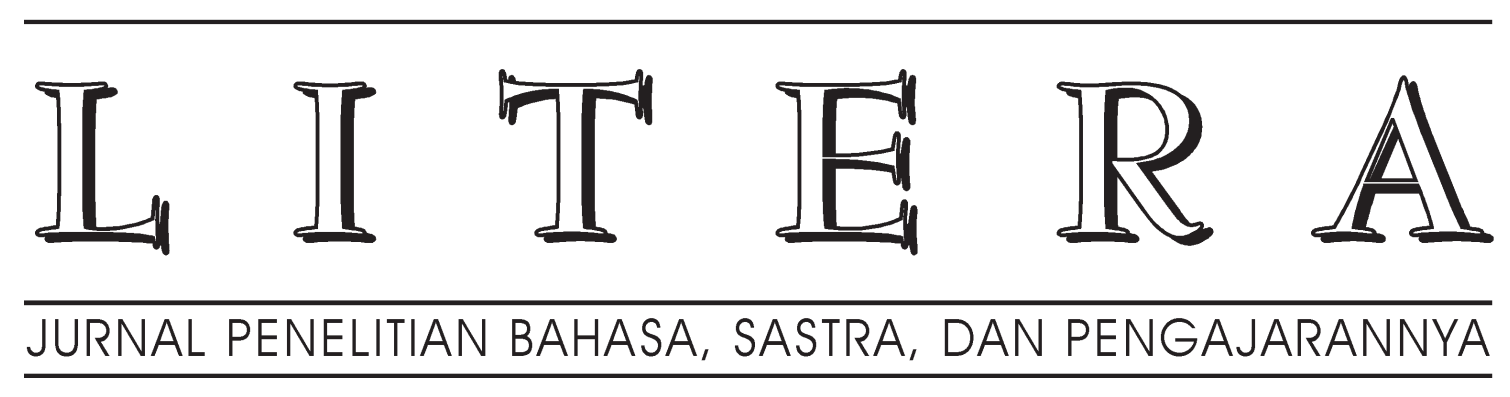

Berdasarkan SK Dirjen Dikti Nomor: 66b/DIKTI/Kep/2011, tanggal 9 September 2011 tentang Hasil Akreditasi Terbitan Berkala Ilmiah, LITERA dinyatakan sebagai Terbitan Berkala Ilmiah Terakreditasi, periode Agustus 2011 sampai dengan Agustus 2016 


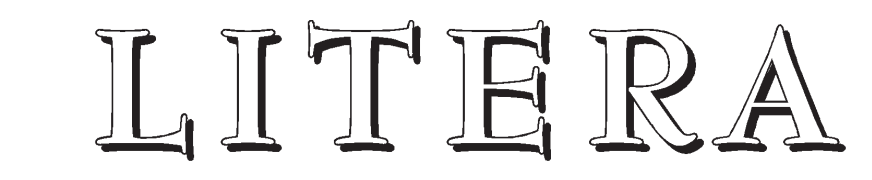

Jurnal Penelitian Bahasa, Sastra, dan Pengajarannya

Volume 12, Nomor 1, April 2013

* Serat Madu Tata Krami dan Relevansinya dengan Pendidikan Karakter $119-128$ Sunaryadi 


\title{
SERAT MADU TATA KRAMI \\ DAN RELEVANSINYA DENGAN PENDIDIKAN KARAKTER
}

\author{
Sunaryadi \\ Fakultas Seni Pertunjukan ISI Yogyakarta \\ e-mail: kabanram@yahoo.com
}

\begin{abstract}
Abstrak
Penelitian ini bertujuan mengungkapkan nilai-nilai dalam Serat Madu Tata Krami yang terimplikasikan pada filsafat Joged Mataram dan relevansinya dengan pendidikan karakter. Sumber data adalah Serat Madu Tata Krami koleksi pribadi K.P.H. Brongtodiningrat, berbentuk tembang macapat, berbahasa, dan berhuruf Jawa gagrag Mataram (Jawa Baru). Penelitian menggunakan metode deskriptif kualitatif. Hasil penelitian menunjukkan bahwa nilai-nilai yang diajarkan dalam Serat Madu Tata Krami dapat dijadikan sebagai nilai dasar untuk pendidikan karakter. Nilai-nilai tersebut berkaitan harapan, nasihat, petunjuk, dan keyakinan bahwa memperjuangkan kebenaran dan kebaikan akan selalu berhasil. Ajaran dalam Serat Madu Tata Krami tidak bias dipisahkan dari filsafat Joged Mataram yang berpegang pada nilai kasatria dalam menghadapi semua masalah kehidupan dengan pedoman falsafah sawiji, greget, sengguh, dan ora mingkuh.
\end{abstract}

Kata kunci: Joged Mataram, nilai dasar, pendidikan karakter

\section{SERAT MADU TATA KRAMI AND ITS RELEVANCE TO CHARACTER EDUCATION}

\begin{abstract}
This study aims to reveal values in Serat Madu Tata Kramireflected in the philosophy of Joged Mataramand its relevance to character education. The data source was Serat Madu Tata Krami, K.P.H. Brongtodiningrat's private collection. The work is in the form of macapat songs, written in Javanese using the Javanese alphabet in the Mataram style (the modern Javanese). This study employed the qualitative descriptive method. The findings show that the values in Serat Madu Tata Kramican serve as basic values for character education. The values are related to expectation, advice, suggestion, and belief that struggling for truth and virtue will always succeed. The teaching in Serat Madu Tata Krami cannot be separated from the philosophy of Joged Mataram, which holds the gallant values to face all life problems using the philosophy of sawiji, greget, sengguh, and ora mingkuh.
\end{abstract}

Keywords: Joged Mataram, basic values, character education

\section{PENDAHULUAN}

Salah satu akibat yang tidak terhindarkan dari proses globalisasi adalah masuknya beragam nilai yang berasal dari "luar" dan memberi warna tersendiri pada sendi-sendi kehidupan budaya bangsa. Nilai-nilai tersebut tidak selalu sesuai, bahkan seringkali bertentangan dengan nilai yang sudah terinternalisasi dalam kehidupan masyarakat. Akibat yang lebih jauh, karakter dan nilai-nilai keindonesiaan sebagai identitas bangsa, makin pudar dan mulai dilupakan (Sayuti, 2012:7). Dalam hubungan ini, pendidikan karakter yang berbasis pada nilai-nilai luhur budaya bangsa menjadi upaya yang 
tidak bisa ditunda-tunda lagi. Pendidikan karakter dalam arti luas bertujuan untuk menyiapkan dan mewujudkan masyarakat-bangsa yang berketuhanan, berperikemanusiaan, berjiwa persatuan, berjiwa kerakyatan, yang berdasar pada permusyawaratan, dan berkeadilan sosial. Oleh karena itu, penggalian nilai-nilai luhur tersebut, yang banyak tersimpan dalam berbagai artefak perlu dilakukan, yakni artefak-artefak yang tersebar di seluruh wilayah geokultural Nusantara, termasuk Jawa (Mataram). Tujuannya, agar hasil penggalian yang dilakukan dapat dijadikan alternatif nilai, baik sebagai nilai dasar yang perlu direvitalisasi atau direkontekstualisasikan dengan perkembangan peradaban maupun sebagai nilai dasar yang dijadikan pijakan pengembangan atau pembentukan nilai baru yang sesuai dengan karakter kebangsaan.

Selain itu, pada era global ini di mana pertukarandan persebaraninformasiantarnegara demikian pesat mengakibatkan perubahan budaya yang sangat cepat pula. Tujuan hidup manusiapun berubah bukan bagaimana orang harus mempunyai 'budi luhur', bermoral, dan berkarakter baik, tetapi bagaimana menjadi 'sukses' (nilai guna). Kesuksesan di sini mempunyai keterikatan dengan nilai sosial dan politik yang melihat orang lain sebagai yang harus dikalahkan, dan imbasnya menimbulkan konflik di segala bidang. Tidak ada lagi toleransi, yang ada hanyalah 'ego' untuk lebih dari orang lain, materialistik, individualistis, dan egosentris.

Sehubungan dengan itu pembentukan dan pembinaan karakter perlu dinomorsatukan dengan melalui berbagai cara. Di antaranya dengan menggali kembali nilai-nilai luhur budaya bangsa, baik yang berasal dari sebuah karya sastra, atau yang berupa seni pertunjukan (tari) dan lainnya, yang sarat dengan ajaran moral sebagai pembentuk karakter.

Dalam hubungannya dengan Joged Mataram, dapat dilakukan secara ber- tahap melalui pemahaman terhadap konsep sawiji atau nyawiji. Sawiji menyembah kepada Tuhan, melatih orang untuk berserah diri kepadaNya dengan cara menenangkan batin (eneng/meneng) dan mengendapkan pikiran (ening) yang disertai rasa eling bahwa manusia 'mung sakderma nglakoni' sehingga hidupnya menjadi tenang. Hati yang bersih (bening/wening) akan dapat mengontrol diri dalam berperilaku, karena disadari bahwa manusia lahir, menjalani hidup, dan akan kembali kepadaNya. Untuk itu, manusia perlu menjalani hidup yang baik, banyak berbuat kebajikan, serta asih terhadap sesama.

Selama ini, apabila nilai-nilai luhur budaya Jawa khususnyaYogyakarta yang dibicarakan, maka filsafat Joged Mataram turut menempati posisi penting. Hal ini bisa dipahami karena filsafat tersebut sangat erat kaitannnya dengan kehidupan budaya kraton, khususnya tari dan penarinya. Akan tetapi, hal itu tidak berarti bahwa tidak terdapat sumber lain yang relevan, dan tidak pula berarti bahwa Joged Mataram hanya berlaku bagi tari dan penari. Nilai-nilai filosofis tersebut juga signifikan bagi kehidupan keseharian. Bahkan, sangat dimungkinkan bahwa Joged Mataram merupakan nilai-nilai filsafat yang dirumuskan berdasarkan naskah atau sumber tertentu. Penelitian ini berupaya mengungkapkan nilai-nilai Serat Madu Tata Krami dalam kaitannya dengan rumusan Joged Mataram, sebagai nilai-nilai yang relevan dengan pendidikan karakter bangsa.

\section{METODE}

Serat Madu Tata Krami yang menjadi sumber data penelitian merupakan koleksi pribadi K.P.H. Brongtodiningrat, berbentuk tembang Macapat, berbahasa dan berhuruf Jawa gagrag Mataram (Jawa Baru). Tebal naskah 293 halaman, setiap halaman terdiri 21 baris, dengan margin kiri 2,5 cm, atas $4,3 \mathrm{~cm}$, margin kanan 
$4 \mathrm{~cm}$, dan margin bawah 4,9 cm. Bahan naskah menggunakan kertas Eropa berukuran 33 X 20,5 cm.

Metode penelitian yang dipakai untuk mengungkap nilai-nilai dalam Serat Madu Tata Krami adalah metode deskriptifkualitatif. Metode ini digunakan karena menyangkut pengertian tentang nilai dari sebuah karya sastra, bagaimana nilai-nilai itu berpengaruh pada filsafat Joged Mataram sebagai dasar pembentuk karakter dalam kehidupan keraton, dan relevansinya dengan kehidupan masyarakat saat ini. Objek material penelitian berkaitan dengan nilai-nilai, dalam penelitian ini digunakan pula metode kualitatif naturalistik yang bersifat grounded (Kaelan, 2005: 57).

\section{HASIL DAN PEMBAHASAN Penulis dan Penulisan Serat Madu Tata Krami}

Naskah SeratMadu Tata Krami termasuk genre sastra dedaktis karena memuat ajaran moral Jawa. Matriks ajaran tersebut adalah pepali Kyai Ageng Abdulrachman (yang dikenal dengan sebutan Ki Ageng Sela), keturunan Prabu Brawijaya (Raja Majapahit), yang hidup pada jaman Demak abad XIV. Ki Ageng Selamemilih menjadi petani dan mengembangkan ajarannya kepada anak keturunannya. Ki Ageng Sela berputra Ki Ageng Nis yang menurunkan Ki Ageng Pemanahan. Ki Ageng Pemanahan berputra Danang Sutawijaya atau Panembahan Senapati yang kemudian menurunkan raja-raja Mataram di Surakarta dan Yogyakarta (Bratadiningrat, 1988:15).

Serat Madu Tata Krami ditulis oleh seorang Bupati Kraton Yogyakarta bernama Kyai Abdul Zalil pada tahun 1830, dan dipersembahkan kepada Sri Sultan Hamengku Buwana VI. Kutipan yang berisi candra sengkala berikut ini menunjukkan hal tersebut.

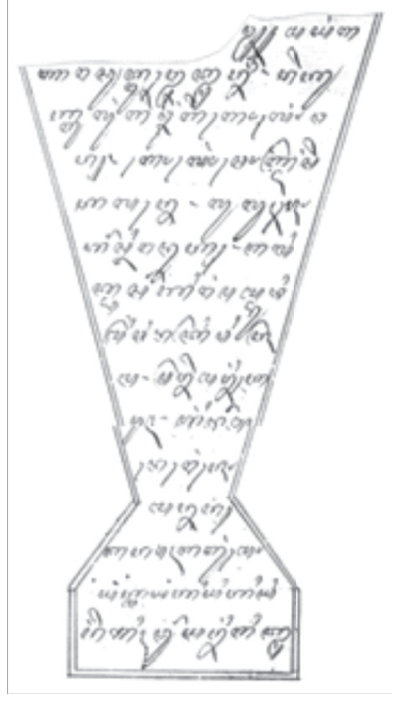

(Naskah asli tulisan tangan)

Mayanggana racut runcetaning nkuk gulung golong gegolongan golong candrasngkalane luluh (0)jobar [3] slira(8) duk (1):1830 alit dhasar kirang pambudi mring wida triwikrama pranmaning kewuh ing darma dereng komanan tansah agung moyak maya kiyi-kiyi nnggih wuryaning gita. (Abdul Zalil, 1830, pupuh Dhandhanggula, bait 2, halaman.1; selanjutnya pupuh disingkat pp; Dandhanggula disingkat $\mathrm{D}$; bait disingkat $\mathrm{b}$ )

\section{Artinya:}

Keindahan piwulang ini diurai dicari intinya/ruhnya/piwulang ini harus dipahami secara utuh/menjadi kesatuan antara peristiwa dan tahun terjadinya $1830 /$ menjiwai piwulang luhur menyatu dengan jiwa raga/ syair ini sebenarnya sederhana/tetapi apabila di dalami besar manfaatnya/ orang harus selalu waspada/piwulang ini belum banyak diterapkan/selalu mendapatkan keluhuran yang mengalir dengan sendirinya/demikian awal syair ini). 
Dalam kutipan tersebut didapatkan kata-kata luluh (0) kobar (3) slira (8) duk (1) sebagai sengkalan yang menunjukkan angka tahun dituliskannya kembali serat tersebut, yakni tahun 1830. Selanjutnya, dituliskan pula pupuh berikut ini.

Kang hamngku ing nuring rat kabir

ya ming ngatak kayuyun bawengrat

bbaya bali budine

tikanang sabiyantu

sangking tata ingkang tinguding

ttp titi bksanta

kanging ingkang sinuwun

tandha stern winula

kang kaping nm jumnng Ngayugya nagri jawata ngejawantah.

(Abdul Zalil, 1830: pp. D.b.4), h.2

Artinya:

Yang memangku cahaya dunia (kemuliaan), hanya mengingatkan (yang disebabkan karena) terpesona dengan perbawa dunia, bahaya (cobaan yang dapat) mengembalikan budi, itulah (sebagai cara untuk) membantu, (yang) berasal dari tatanan (yang tetap) ditaati, tetap tekun menjalani, (sebagai) tanda bakti hamba pada Yang Mulia Kanjeng Sinuwun, yang bertahta ke enam di negeri Yogyakarta, (bagaikan) dewa (yang) menitis di dunia.

Ingkang ngarang Madu Tata Krami

kyai tan ning Abdul Zalil ika

risang nararya ya rame

ing kulon prajanipun

kang piniji dadi bupati

/kuluring manah kacipta

dadya annungku

tumdhaka ingkang brkah

den lakoni andhap asor ngati-ati

tabri marang praja.

(Abdul Zalil, 1830:pp.D,b.10), h.3.

Artinya:

Yang mengarang Madu Tata Krami adalah Kyai Abdul Zalil, yang menjadi penguasa, di tanah barat kekuasaannya, yang dipilih menjadi seorang bupati, dari hati yang tulus berharap, menjadi doa, (agar) berbuatlah yang berkah, (dengan jalan) dilaksanakan dengan penuh rendah hati dan berhati-hati, tekun (mengabdi tanpa pamrih) terhadap pemerintah (kerajaan pada jamannya).

\section{Nilai-nilai dalam Serat Madu Tata Kramidan Relevansinya dengan Pen- didikan Karakter}

\section{Kandungan Nilai Sawiji}

Nilai-nilai dalam Joged Mararam yang terdiri dari sawiji, greged, sengguh, ora mingkuh, sekalipun berangkat dari nilainilai yang ada dalam tari, akan tetapi nilai filsafatnya dapat diterapkan di mana saja, dalam berbagai kondisi dan situasi, bahkan menjadi landasan dasar budaya Yogyakarta. Kuntowijoyo mengatakan bahwa nilai-nilai dalam tari Kraton Yogyakarta bisa dijadikan acuan hidup bagi masyarakat Jawa (Kuntowijoyo, 1987: 24).

Konsep simbolik Joged Mataram dalam kaitannya dengan kehidupan bermasyarakat dan pendidikan karakter itu, ternyata telah terjabarkan dalam pepali Ki Ageng Sela yang tertulis di dalam Serat Madu Tata Krami karya Kyai Abdul Zalil. Menurut Ki Ageng Sela dalam pupuh Dhandhanggula (pp.D,b.30, h.9), sawiji adalah:

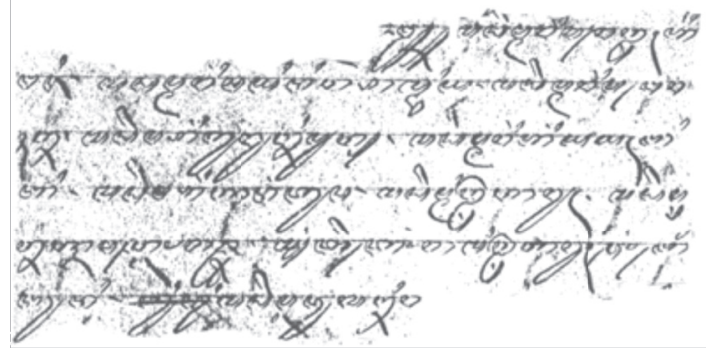

Madhep maring parentahing aji; madhep maring sayidin ambiya; madhep maring pangerane; 
madhep ing gurunipun;

madhep maring ing yayah bibi;

madhep ing kadang tuwa;

madhep mitra karuh;

madhep sanak lawan kanca;

myang tetanggamintrakaruhwongberbudi;

madhep kawulanira.

(Abdul Zalil, 1830: pp.D,b.30, h.9).

Artinya:

Mantap berbakti pada raja; berbakti pada para nabi; berbakti pada Tuhan; berbakti pada guru; berbakti pada ayah ibu; berbakti pada saudara tua; berbakti (baik, sopan) pada mitra; berbakti (hormat) pada saudara dan teman; serta berbudi pada tetangga; hormat pada rakyatnya (bawahannya).

Ajaran itu ditegaskan lagi dalam tembang Asmaradana berikutnya yang berisi tentang cara menjalankan konsep sawiji, berbunyi:

Ngestu puja lan semedi,

ambeke amung ngibadah,

lan marih ngadil niyate,

seca tuhu mring nalendra,

gemeni tata krama,

kulina ngagama tuhu, manguntur tindak raharja

(Abdul Zalil,1830.ppA.b5)

Artinya: Dengan tulus konsentrasi untuk menyatu dan berdoa, hanya menjalankan ibadah dan menerima pemberianNya dengan ikhlas, setia pada raja, selalu menaati sopan santun, selalu menjalankan perintah agama, selalu berbuat baik.

Pernyataan itu diperkuat dengan pepeling dalam pupuh tembang Asmaradana berikutnya yang berbunyi:

Enget titahing dumadi, angantepi krana Allah, muhung lilahing kalbune, sabar barang kang sineja, sukuring ing wardaya, ngadohi larangan mulku,

wedi siksaning ywang suksma.

(Abdul Zalil,1830. ppA.b6)

Artinya:

Ingat akan asal mulanya, Ikhlas karena Alah Ta'ala, hanya mengharapkeridhoannya, selalu sabar dan hatinya selalu bersyukur, menjauhi larangan Allah, takut akan siksa-Nya.

Sawiji terhadap Tuhan dan ajaranajarannya, menjadikan manusia selalu berhati-hati dalam bersikap, berbicara dan berperilaku, dengan demikian akan tumbuh tenggang rasa terhadap keselamatan dan kesejahteraan bersama. Rasa sawiji dalam arti hidup bermasyarakat dan berbangsa, akan menumbuhkan rasa melu handarbeni wajib hangrungkepi, dan mulat sarira hangrasa wani, sehingga mampu bersikap adil, bijaksana dalam mengambil keputusan, tidak pilih kasih, dan saling melindungi. Dengan sikap yang berpangkal pada kehendak nyawiji itu niscaya akan tumbuh manusia-manusia yang berbudi, legawa, sabar, mampu memahami aspirasi orang banyak. Semua itu merupakan ajaran moral yang kiranya masih relevan di era modernisasi yang serba gemerlap dengan godaan duniawi seperti sekarang ini, di mana kebersamaan dan rasa saling asih itu telah tenggelam oleh ego masing-masing.

Konsep nyawiji tidak hanya berorientasi kepada tindakan individual saja, tetapi juga dalam sistem kemasyarakatan, sebagaimana ditunjukkan pada sikap gotong royong. Gotong royong merupakan perwujudan sikap yang diharapkan mampu menciptakan rasa golong-gilig dan saiyeg-saeka kapti, sebagai satunya kata dan perbuatan dalam rangka memelihara keselarasan hidup. Di dalam faham Jawa, juga berlaku falsafah sadermanglakoni yang berorientasi pada keharmonisan hidup. Berangkat dari konsep saderma nglakoni itu, setiap orang akan menjalankan tu- 
gasnya masing-masing dengan sebaikbaiknya sesuai hak dan kewajibannya berdasarkan pada kodratnya. Kondisi seperti itu akan mempermudah tercapainya cita-cita bersama mengenai sebuah masyarakat atau negara yang 'ing ngarsa sung tuladha, ing madya mangun karsa, tut wuri handayani' seperti diuraikan dalam konsep kepemimpinan Ki Hajar Dewantara

Prinsip hidup tersebut oleh orang Jawa diungkapkan dalam kata neng-ning-nungnang (Endraswara, 2003: 95). Enang artinya menang, berhasil mengalahkan nafsu atau keinginan pribadinya. Dari kondisi hening akan tercapai pengendalian diri yang maksimal. G.B.P.H. Suryobrongto menafsirkan makna sawiji adalah konsentrasi pada kesanggupan untuk menyatukan kemauan dengan mengerahkan seluruh kekuatan rohani dan pikiran ke arah sasaran yang jelas, dan melakukannya secara terus-menerus (Suryobrongto, 1982:7). Berdasarkan uraian tersebut, terlihat bahwa relevansi sawiji pada kehidupan masyarakat Jawa, adalah dalam upaya menyatukan rasa saling memiliki antar individu dalam masyarakat.

\section{Kandungan Nilai Greged}

Greged atau semangat, mendorong tekad untuk mengejar harapan, dan mewujudkannya dengan bekerja keras. Orang yang mempunyai greged atau semangat pastilah memiliki target untuk meraih prestasi. Namun demikian, perlu disadari bahwa semangat yang berlebihan akan membuat orang lupa diri, dan akhirnya akan menggerakkan keinginan (pepinginan) yang tidak terkendali, baik keinginan mengedepankan golongannya, kekuasaannya, kedudukan, atau materinya.

Di dalam naskah Madu Tata Krami, greged dinyatakan sebagai: "Atrangginas rumêgsaning dadi..., yang berarti cakap dalam bertindak, dan dengan semangat (greged) pasti akan membuahkan hasil
(Abdul Zalil, 1830. pp D, b.26.). Gregedharus disalurkan dan dijalankan dengan tenang, sabar, penuh perhitungan tidak grusah-grusuh atau asal-asalan. Greged yang terkendali akan mematangkan jiwa dan batin manusia, sehingga terbina ketenteraman bagi diri sendiri dan orangorang di sekitarnya.

\section{Kandungan Nilai Sengguh}

Implementasi sengguh dalam kehidupan sehari-hari identik dengan rasa percaya diri. Percaya diri menurut etika Jawa, haruslah berlandaskan pada ajaran 'ngesthi pribadi' artinya tidak individual atau mengedepankan egonya, tidak menjadi sombong. Percaya diri dalam hal ini mengandung pengertian 'aja golek menange dewe', menganggap dirinya yang paling baik, paling benar. Seseorang yang penuh percaya diriseharusnya tidak mengabdi hawa nafsu memamerkan kedudukan, kepandaian, dan kekuasaannya (aja ngumbar hawa nafsu, adigang, adigung, adiguna), tetapi justru dengan kepercayaaanya itu,orang berani mengalah (wani ngalah) untuk tujuan yang lebih mulia. Orang yang bisa menempatkan sengguh dalam proporsi yang benar, hidupnya tertib, teratur, dan tidak jarang sikapnya pun andhap asor, karena percaya bahwa Tuhan memberikan sesuatu yang lebih, yang harus dibagikan kepada sesamanya.

Dalam Serat Madu Tata Krami dinyatakan bahwa sengguh harus diterapkan dengan benar pada orang-orang tertentu atau keadaan tertentu, seperti tertulis pada pupuh berikut ini.

Sengguh ing wong kang mêrkata budi, sengguh bares ingkang tepatakan,

sengguh bares wicarane,

sengguh tenaga luruh,

sengguh ulat manis prak ati,

sengguh raga kerana,

sengguh bisa tuhu,

sengguh taberi gegulang,

sengguh tata ana sengguh kaya santri, sengguh kaya wong kumpra. 
(Abdul Zalil, Sela,1830.pp.D. b.21)

\section{Artinya:}

Sengguh pada orang yang ingin memiliki budi baik, sengguh (itu) lugu(dan) ramah dalam bergaul, sengguh (dalam) berkarya (jiwa dan raga), sengguh dengan kesungguhan, sengguh (dalam) tekun belajar (berlatih), sengguh (itu) ada tatanannya, sengguh seperti seorang santri, ada yang seperti orang sudra (kumpra).

Selanjutnya, disebutkan bahwa sengguh harus didasari rasa iklas dan laku prihatin agar hati tetap suci dan tidak menyombongkan diri:

Iklasing galih cinandhing, amrih slamêt nuraga

trima dhuruk ing bodhone

pintêre ora rumangsa

naming darma kewala

lamun kinarya yang agung

lir sarah munggeng samodra

(Abdul Zalil,Sela, 1830, ppA, b.7)

\section{Artinya:}

Hati harus ikhlas agar selamat sentosa, tidak menyombongkan diri, tidak merasa pandai, hanya berbuat baik selalu, ikhlas karena Allah, kesabaran tanpa batas bagaikan samudra). Dengan demikian, pengertian sengguh sebagai pedoman hidup berkenaan dengan sikap penuh percaya diri dan tetap terkendali, yakni bersikap teguh dan tidak menyombongkan kelebihan yang dimiliki atau dikuasainya.

\section{Kandungan Nilai Ora Mingkuh}

Ora mingkuh merupakan tataran terakhir yang saling terkait dengan tiga ajaran sebelumnya (sawiji, greget, sengguh). Ora mingkuh juga berarti mampu melepaskan segala perasaan serta mampu menggunakan logika sebagai pegangan dalam bertindak. Ora mingkuh merupakan ekspresi dari sikap tanggung jawab, dan sikap tegas (ora mingkuh). Manifestasi sikap ini berupa 'jalma tan kena kinira' (sikapnya tidak dapat diduga), karena tidak membeda-bedakan martabat dan derajat seseorang. Sikap tegas bukan berarti memegang teguh sebuah prinsip dengan harga mati yang tak bisa ditolerir, tetapi dalam sikap ora mingkuh itu tetap terkandung adanya toleransi.

Dalam etika Jawa 'teguh'artinya tetap harus lentur melihat situasi dan kondisi, yang dalam konsep Jawa disebut sebagai ngerti empan papan (tahu menempakan diri). Ora mingkuh dalam hal ini lebih condong pada pengertian bahwa seseorang haruslah memiliki sifat teteg (mantab), tatag (memandang ke depan), serta teguh atau jejeg berdiri tegak dan kokoh. Orang yang demikian akan sentosa ing budi tidak mudah goyah dalam pendirian, serta mampu menjadi pelindung, berani menegakkan keadilan, karena dapat mengatur dorongan nafsu pribadi (bisa meper pepinginan). Manusia yang berwatak ora mingkuh akan mengedepankan prinsip ora gumunan (tidak mudah mengagumi sesuatu), dan ora kagetan (tidak mudah kaget menghadap baik buruknya keadaan dan iming-iming yang ditawarkan). Untuk itu manusia harus mampu mengatur panca indera dengan cara nutupi babahan hawa sanga, artinya menutup semua melik atau keinginan yang kurang baik, serta mampu berwawasan objektif dalam memandang setiap peristiwa.

Filsafat hidup Jawa, selain yang telah disebutkan di atas, juga menekankan pada sikap hidup yang berbudi bawa laksana yang memiliki arti suka berdarma dan menepati segala yang telah diucapkannya. Setiap orang hendaknya satu kata satu perbuatan, sesuai antara apa yang diucapkan dengan apa yang dilakukannya, karena perilaku adalah cermin dari watak atau karakternya. Uraian itu menunjukkan bahwa orang Jawa harus serius dalam melaksanakan segala aktivitas, seperti ditunjukkan dalam Serat Madu Tata Krami 
pada tembang Dhandhanggula berikut:

Sayogyane temen lan taberi

sayogyane ambêg kumawula

sayogya alus nalare

sayogya wruh ing tuduh

sogyane legawa kang galih

sayogya ambeg tapa, sayogya beg luhur

sayogyane ambeg marma

sayogya ambeciki ing pakarti

sayogya tanpa dama.

(Abdul zalil, Sela. 1830.pp.D:baid 140)

Artinya:

Hendaklah sungguh-sungguh, pantang mundur dan tekun, hendaklah berbudi luhur (dan) merakyat, hendaklah memilki nalar yang halus (baik), hendaknya mengerti (tentang) petunjuk (nasihat), hendaknya memiliki hati yang ikhlas (legawa), hendaknya bersikap (seperti seorang) pertapa, hendaknya berbudi luhur, hendaknya welas asih (pada sesama), berbuat baik dalam perbuatan, hendaklah tanpa pamrih.

Tembang itu secara jelas mengajarkan kepada kita tentang kehidupan yang baik dan benar menurut norma keluhuran. Baris-baris (gatra) tembang tersebut apabila dicermati bukanlah sebuah paparan yang linier, tetapi merupakan hukum sebab-akibat yang berlaku dalam realitas hidup. Dalam mengemban hak dan kuwajiban atas profesi apapun harus dilaksanakan dengan serius dan tekun. Seandainya sebagai pimpinan haruslah memperhatikan kepentingan rakyat karena bagaimanapun juga seorang pemimpin ada apabila ada rakyat. Oleh karena itu kita harus berbudi luhur dan rendah hati. Kerendahan hati akan mengusir sikap sombong dan merasa paling pandai, atau paling benar. Hanya dengan cara demikianlah kita mau menerima segala petuah atau nasehat dari siapapun. Di samping itu juga akan menumbuhkan kesadaran atas segala kekurangan diri sendiri dan menghargai kelebihan orang lain (nglenggana).

Prayogyane arerasa bêcik

prayogane manising pulatan

prayoga jinem lungguhe

prayoga entang luruh

prayogane amrakateni

prayoga kang presaja

prayoga kang malum

prayoga marnata kra-[h. 5]ma

prayogane alembah nora kesingkir

prayoga kang ajriyan.

(Abdul Zalil, 1830. pp. D: bait 15)

Artinya:

Hendaklah berprasangka baik, hendaklah memiliki sikap manis, hendaklah tenang (dalam) duduk, hendaklah ramah, hendaknya (bersikap) menyenangkan hati, hendaklah bersahaja, hendaklah yang maklum, hendaknya menata (sikap) perbuatan, hendaknya rendah hati (agar) tidak tersingkir (dimusuhi), hendaklah takut (tidak sombong, bergaya sok).

Manusia harus selalu berprasangka baik, bersahaja, rendah hati, dan menyenangkan sesamanya, seperti tertulis dalam tembang Dandhanggula berikut:

Papantese olahing dedugi

papantese olah kawibawan

pantes ulah kaprawirane

pantes ulah ing tembung

pantes ulah pranata titi

pantes ulah ukara

pantes ulah nujum

panteês ulah dasanama

pantes ulah pigunan yuda negari

pantes ulah ing praja.

(Abdul Zalil, ppD.b.16)

Artinya:

Pantaslah berolah pengetahuan, pantaslah berolah wibawa, pantas berolah kekuatan (keberanian), pantaslah berolah kata, pantaslah berolah (segala) pranata (peraturan) dengan teliti, 
pantaslah berolah kalimat, pantaslah berolah nujum (ramalan, perbintangan), pantaslah berolah dasanama (berbagai julukan, nama-nama), pantaslah berolah segala pengetahuan bela negara, pantaslah berolah tata negara.

Selain ajaran tersebut manusia Jawa juga disarankan untuk selalu berpegang pada budi baik dan ilmu pengetahuan seperti berikut:

Akal iku dadi uwit

budi jenenge tumandang

nalar ing kadadeane

pekiriku duk kawawang

sampurnane punika, yen mufakat lawan ngelmu

lilahi jumênêng apa.

(Abdul Zalil, Sela, ppA.b.28)

Artinya:

Akal itu menjadi pegangan, budi yang menuntun pada perbuatan, bisa terwujud sarana nalar (yang baik), diawali dari pikiran (yang baik), agar menjadi sempurna maka harus disertai dengan ilmu pengetahuan, dari Ilahi Yang Maha Kuasa.

Akal menjadi pegangan, budi yang menuntun perbuatan, bisa terwujud karena nalar (budi baik) diawali dari pikiran yang baik, agar menjadi sempurna maka harus disertai dengan ilmu pengetahuan dari Yang Maha Kuasa. Saat seseorang berpegang pada budi baik dan ilmu pengetahuan yang berasal dari Tuhan, meski mengalami banyak kesulitan di dalam hidup, tetapi harus selalu percaya pada keadilan Yang Maha Kuasa

Deskripsi berbagai pepeling di atas menguatkan bahwa sumber dan asal muasal Joged Mataram, memang sejatinya merupakan implementasi pepali Ki Ageng Sela yang terangkum dalam Serat Madu Tata Krami, dan layak dijadikan sebagai pembentuk karakter bangsa. Pendidikan karakter yang harus dilakukan sejak masa kanak-kanak, karena karakter bukan bawaan sejak lahir, tetapi dibentuk melalui pendidikan, pengalaman, dan lingkungan. Kamus Webster's New World Dictionary mengartikan karakter sebagai watak yang kuat (moral strenght self discipline, fortitude), tetapi menurut Pusat Bahasa Depdiknas (2010: 2-19) pengertian karakter adalah bawaan, hati, jiwa, kepribadian, budi pekerti, perilaku, sifat, tabiat, watak, temperamen, atau personalitas. Faktor yang mempengaruhi terbentuknya karakter diantaranya adalah moral (sifat baik dan buruk), agama, kebijakan pemerintah, hukum, sejarah, nilai-nilai, sopan santun, tata krama yang berlaku pada lingkungan atau komunitas atau suku tertentu. Oleh sebab itu, cara untuk menanamkan karakter adalah dengan mensosialisasikan, menginternalisasi nilai-nilai yang bersumber pada budaya setempat, serta membangun budi pekerti manusianya (keteraturan perilaku, sebagai hasil perpaduan antara bakat bawaan dengan pengaruh pendidikan dan pengaruh lingkungan). Menurut para ahli psikologi, nilai karakter dasar manusia berupa cinta kepada Allah dan ciptaannya, mempunyai rasa tanggung jawab, jujur, hormat dan santun, kasih sayang, percaya diri, toleransi, disiplin, cinta damai, punya integritas, adil, dan mempunyai jiwa kepemimpinan (Amri, 2011: 3). Penjabaran dari nilai karakter dasar itu ternyata semuanya ada di dalam makna Joged Mataram sebagai pembentuk karakter para kerabat kraton dan masyarakatnya, seperti terjabarkan dalam kata hamangku (murah hati dan teguh pada ucapannya/sabda pandhita ratu), hamengku (bersifat melindungi, dan bersikap adil) dan hamangkoni (bertanggungjawab pada perbuatan dan keputusan yang diambil).Di sini terlihat bahwa penanaman karakter yang berdasar pada nilai-nilai luhur budaya setempat, masih diperlukan untuk mengimbangi persaingan global dan memperkuat jati diri guna memperkokoh ketahanan nasional. 


\section{SIMPULAN}

Berdasarkan uraian di atas tampak jelas bahwa ajaran dalam Serat Madu Tata Krami yang terimplikasikan dalam filsafat Joged Mataram bukan saja sebagai ajaran di bidang tari, tetapi sekaligus terimplikasikan dalam realitas kehidupan sehari-hari. Petuah-petuah itu mengajarkan nilai-nilai untuk berpegang teguh pada kebenaran. Nilai-nilai yang diajarkan dalam Serat Madu Tata Krami dapat dijadikan nilai dasar yang berpotensi besar untuk dikembangkan dalam rangka pendidikan karakter. Seperti dalam pewayangan, selalu diceritakan bahwa "pada akhirnya kebenaran pasti akan menang atau mendapat pahala". Hal tersebut bukan hanya sebuah konsep idealisme semata, namun lebih merupakan harapan, nasihat, petunjuk, dan keyakinan bahwa dengan memperjuangkan kebenaran dan kebaikan yang berpegang pada falsafah sawiji, greget, sengguh, ora mingkuh, niscaya keberhasilan akan didapat. Dalam pelaksanaannya, sawiji, greget, sengguh, ora mingkuh dapat menjadi filter dari semua perbuatan yang tidak benar. Ajaran dalam Serat Madu Tata Krami telah memberikan contoh pedoman hidup bagi masyarakat dengan melalui filsafat Joged Mataramyang berpegang pada nilai kasatria dalam menghadapi semua masalah kehidupan.

\section{UCAPAN TERIMA KASIH}

Artikel ini diangkat dari sebagian disertasi yang penelitiannya dilakukan pada tahun 2008. Penelitian ini dilakukan dalam rangka melengkapi syarat memperoleh gelar doktor bidang ilmu Filsafat di Fakultas Filsafat Universitas Gadjah Mada Yogyakarta 2012. Oleh karena itu, penulis sampaikan ucapan terima kasih kepada Prof. Dr. Lasiyo, M.A., M.M., Prof. Dr. Kaelan, M.S., Prof Dr. Soetarno, DEA. selaku promotor dan ko-promotor. Ucapan terima kasih juga kami sampaikan kepada Prof. Dr. Suminto A. Sayuti selaku reviewer yang telah mengoreksi dan memberi masukan terhadap artikel ini.

\section{DAFTAR PUSTAKA}

Amri, Sofan, 2011. Implementasi Pendidikan Karakter dalam Pembelajaran. Surabaya: Prestasi Pustaka Publisher

Bratadiningrat, G.R.Ay., 1988. Asal Usulipun Para Nata. Surakarta: tp.

Depdiknas. 2010, 2010. Pembangunan Karakter Bangsa, Tanpa nama penulis Jakarta: Direktorat Pembangunan Karakter dan Pekerti Bangsa.

Endraswara, Suwardi, 2003.Mistik Kejawen: Sinkretisme, Simbolisme dan Sufisme dalam Budaya Spiritual Jawa. Yogyakarta: Narasi.

Kaelan, M.S., 2005.Metode Penelitian Kualitatif Bidang Filsafat. Yogyakarta: Paradigma.

Kuntowijoyo, 1987. Budaya dan Masyarakat, Yogyakarta: Tiara Wacana.

Sayuti,Suminto A. 2012. Pengajaran Sastra dan Kearifan Lokal (makalah). Dipresentasikan dalam Seminar Nasional PIBSI XXXIVdi Universitas Jenderal Soedirman pada Selasa, tanggal 30 Oktober 2012.

Suryobrongto, G.B.P.H. 1982. Tari Klasik Gaya Yogyakarta dalam Kawruh Joged Mataram. Yogyakarta: Dewan Ahli Yayasan Siswa Among Beksa Ngayogyakarta Hadiningrat.

Zalil, Kyai Abdul, 1830. Serat Madu Tata Krami. Naskah koleksi pribadi KPH. Brongtodiningrat. 